\title{
Human Influenza Virus Infections
}

\author{
Christin Peteranderl, $\mathrm{PhD}^{1}$ Susanne Herold, MD, $\mathrm{PhD}^{1}$ Carole Schmoldt, $\mathrm{PhD}^{1}$ \\ 1 Department of Internal Medicine II, University of Giessen and \\ Marburg Lung Center (UGMLC), Giessen, Germany \\ Semin Respir Crit Care Med 2016;37:487-500.

\begin{abstract}
Address for correspondence Susanne Herold, MD, PhD, Department of Internal Medicine II, University of Giessen and Marburg Lung Center (UGMLC), Member of the German Center for Lung Research (DZL), Klinkstraße 33, 35392 Giessen, Germany
\end{abstract} \\ (e-mail: Susanne.Herold@innere.med.uni-giessen.de).
}

\begin{abstract}
Keywords

- influenza virus

- seasonal

- pandemic

- pneumonia

- lung injury

- ARDS

- vaccination

- antiviral therapy

Seasonal and pandemic influenza are the two faces of respiratory infections caused by influenza viruses in humans. As seasonal influenza occurs on an annual basis, the circulating virus strains are closely monitored and a yearly updated vaccination is provided, especially to identified risk populations. Nonetheless, influenza virus infection may result in pneumonia and acute respiratory failure, frequently complicated by bacterial coinfection. Pandemics are, in contrary, unexpected rare events related to the emergence of a reassorted human-pathogenic influenza A virus (IAV) strains that often causes increased morbidity and spreads extremely rapidly in the immunologically naive human population, with huge clinical and economic impact. Accordingly, particular efforts are made to advance our knowledge on the disease biology and pathology and recent studies have brought new insights into IAV adaptation mechanisms to the human host, as well as into the key players in disease pathogenesis on the host side. Current antiviral strategies are only efficient at the early stages of the disease and are challenged by the genomic instability of the virus, highlighting the need for novel antiviral therapies targeting the pulmonary host response to improve viral clearance, reduce the risk of bacterial coinfection, and prevent or attenuate acute lung injury. This review article summarizes our current knowledge on the molecular basis of influenza infection and disease progression, the key players in pathogenesis driving severe disease and progression to lung failure, as well as available and envisioned prevention and treatment strategies against influenza virus infection.
\end{abstract}

Influenza viruses cause annually recurrent respiratory disease in humans with significant impact on human health as well as on economy. Although influenza B viruses are almost exclusively found in humans, influenza A viruses (IAVs) circulate in the human population as an annually recurring epidemic disease, and emerge from a huge zoonotic reservoir. Characterized by their ability to rapidly acquire adaptive mutations in a process called antigenic drift, IAV gradually evade the human immune response., ${ }^{1,2}$ Additionally, the special arrangement of viral genetic information on multiple RNA segments allows for mixing genetic information of different IAV strains giving rise to novel, gene-reassorted virus strains, a process called antigenic shift that periodically results in emergence of virus strains with largely altered characteristics and the ability to infect immunologically naive humans with increased pathogenicity during pandemic outbreaks. In this regard, special concern is raised toward zoonotic viruses circulating in birds as well as in swine populations that display high mortality rates when introduced into the human host. So far, these viruses, H7N9 or H5N1 "bird flu" viruses, only have a low replicative potential in humans and rarely transmit between humans, ${ }^{3,4}$ but are feared to adapt to highly efficient human-to-human transmission and are therefore closely monitored. Although influenza viruses usually cause moderate respiratory illness, infection of the lower respiratory tract of humans can result in pneumonia with progression to acute respiratory distress syndrome (ARDS), and death from respiratory failure.
Issue Theme Respiratory Viral Infections; Guest Editor: Sunit K. Singh, PhD
Copyright (c) 2016 by Thieme Medical Publishers, Inc., 333 Seventh Avenue, New York, NY 10001, USA. Tel: +1(212) 584-4662.
DOI http://dx.doi.org/ 10.1055/s-0036-1584801. ISSN 1069-3424. 
Influenza-mediated damage to the alveolar epithelium results from both intrinsic viral pathogenicity attributable to its tropism to alveolar epithelial cells and a robust host immune response, which, although contributing to viral clearance, can worsen the severity of lung injury. Therefore, IAVs pose a substantial threat to global human health and are closely monitored to record local influenza activity to design annual vaccines and to counteract outbreaks of novel strains which have acquired the ability to cross species barriers to infect humans. Besides existing strategies including vaccination and antiviral therapy, showing variable efficacy due to antigenic variation and the occurrence of resistant virus variants, novel approaches have been recently developed to treat influenza virus-induced lung injury by targeting an unbalanced host immune response in addition to antivirals.

In this review, we discuss features and origin of seasonal and pandemic influenza, focused on IAV, its clinical presentation, and current as well as possible future intervention strategies.

\section{Seasonal and Pandemic Influenza}

Two different genera of the virus family Orthomyxoviridae, influenza A and B, can cause a contagious respiratory disease in humans. They cause annual epidemics of varying severity, including mild common cold symptoms to severe lung injury with fatal outcome. IAVs, on which we focus in this review, show a very wide variety and thus are further subgrouped by the antigenic properties of their surface proteins hemagglutinin (HA) and neuraminidase (NA). Besides the well-defined strains circulating in humans (of the subgroups H1N1 and H3N2), IAVs are present in a large number of mammalian species, poultry, and particularly wild birds, with currently 18 or 11 variants known for HA or NA, respectively, where the recently discovered bat-isolates $\mathrm{H} 17 / 18$ and N10/11 seem to be quite distinct from avian and mammalian strains. 5,6

Influenza virus epidemics usually occur during the cold season in temperate regions (Northern hemisphere: December to April; Southern hemisphere: June to September) when low humidity and temperature ambient conditions are suggested to prolong virus shedding and transmission. ${ }^{7}$ In subtropical and tropical regions, influenza seasons are less clearly defined, allowing recurrent infections all over the year. Thus-and due to other reasons such as close proximity to domestic poultry-it has been proposed that the Asian continent represents a particular "reservoir" for not only endemic human but also zoonotic influenza virus strains. ${ }^{8,9}$ Overall, seasonal IAV affects up to $10 \%$ of the adult population and $20 \%$ of children annually ${ }^{10}$ and displays a substantial morbidity. A cohort study estimates that between 2003 and 2009 in the United States, seasonal influenza was responsible for $3.8 \%$ of all admissions for respiratory failure and evaluates the incidence of influenza-associated acute respiratory failure at 2.7 per 100,000 persons per year. ${ }^{11}$ This results in considerable clinical and economic burden. For the United States, direct medical costs covering health care for influenza-induced illness as well as economic losses due to lost working days and declined production are proposed to account for at least 26 billion USD annually. ${ }^{12}$

Compared with the seasonal influenza, pandemics have occurred every 20 to 30 years and are generally associated with more severe symptoms which also affect a healthy young population and potentially lead to increased mortality rates. ${ }^{13-17}$ Pandemic IAV strains are newly introduced into an immunologically naive human population and usually derive from avian reservoirs and have reassorted in an intermediate host such as swine, where they acquire further adaptive mutations, enabling them to infect the human respiratory tract and to effectively transmit from human to human, causing a human disease ${ }^{18,19}$ (- Fig. 1).

Wild birds constitute a primary reservoir of influenza viruses, but IAVs are also widely found in pigs. IAVs have further been identified in other mammalian intermediate hosts, especially aquatic mammals as elephant seals ${ }^{20}$ and also in horses and recently in dogs. ${ }^{21}$ With respect to avian influenza, the major threats for human health currently are influenza A H5N1 and H7N922 widely found in domestic farms and confirmed to induce severe disease in humans. ${ }^{22,23}$ Following a first poultry outbreak at the end of 2003 in Thailand, until now more than 840 cases of human infection with H5N1 have been reported from more than 15 countries ${ }^{24,25}$ with reported mortality rates of more than $50 \%$ and an overall increased morbidity in children $(<15 \text { years })^{26}$; since 2013, poultry-to-human transmission of H7N9 was confirmed in more than 560 cases, leading to severe pneumonia with multiorgan failure and mortality rates of approximately $40 \%{ }^{27,28}$ Interestingly, H7N9 is less pathogenic in birds than H5N1 but displays signatures of human adaptation, as it presents with a better affinity for human than for avian influenza receptors. ${ }^{29,30}$

As the swine respiratory tract expresses both avian and human influenza receptors, ${ }^{31}$ pigs can act as "mixing vessels" for the reassortment of IAV strains from different origins. ${ }^{32}$ The pandemic risk of triple reassortant strains of swine origin has been confirmed during the 2009 "swine" pandemic, where a triple (avian, swine, human) reassortant caused the first pandemic of the 21 th century. ${ }^{19}$

Influenza pandemics constitute a major threat to global health, and emerging strains, in animal reservoirs as well as in the human population, are kept under tight surveillance by the authorities. The World Health Organization (WHO) has defined the progression of a pandemic into six stages, beginning by the first animal infections in phase 1 to the outbreak spreading over a large geographical zone in phase 6 (-Fig. 1), to assess any new pandemic risk (WHO Web site). The Centers for Disease Control and Prevention (CDC) has described a new influenza risk assessment framework (IRAT) to evaluate qualitatively and quantitatively the potential of new strains to give rise to pandemic events based on virus properties, host response of the human population, and the ecology and epidemiology associated with the strain. ${ }^{33}$

Influenza pandemic episodes have been described since the end of the 19th century and virus characteristics as well as associated host responses vary from one pandemic to another. The first, even if less documented, known pandemic was the 


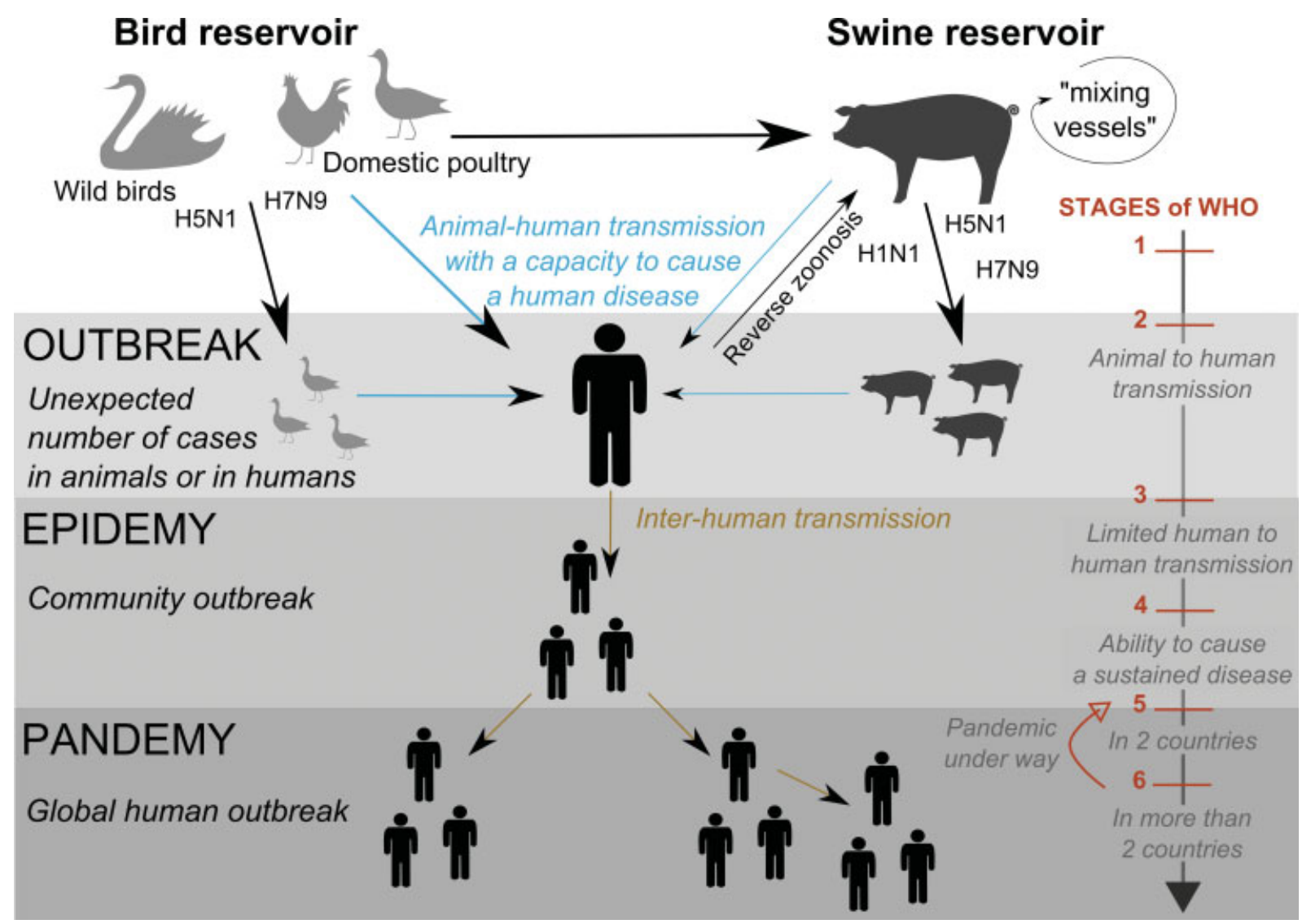

Fig. 1 A schematic representation showing major events involved in emergence of an influenza pandemic, from the two major animal reservoirs to the global outbreak in humans. Evolution steps of emerging strains are attentively followed by World Health Organization and classified into six stages.

1889 "Russian flu" (H3N8) 34 followed by the 1918 "Spanish flu" (H1N1), the "Asian flu" in 1957 (H2N2), ${ }^{35,36}$ the "HongKong flu" in 1968 (H3N2), ${ }^{37}$ and most recently the 2009 "swine flu" (H1N1). Interestingly, the most well-known influenza pandemic, the 1918 Spanish flu, and the most recent pandemic, the swine influenza from 2009, were caused by an H1N1 virus. Also called "the mother of all pandemics" by Taubenberger and Morens, the 1918 virus infected around one-third of the world population and was responsible for the death of at least 50 million of people within a year, appearing in three successive waves. ${ }^{38}$ Although the 1918 pandemic has been extensively studied, the virus characteristics responsible for its fast spread, associated with a high mortality rate especially in the population of 20 to 40 years of age, largely remain obscure. ${ }^{39}$ Yet, studies in mice have shown that the Spanish strain induces a larger immune response, especially in terms of macrophage and neutrophil recruitment, as low pathogenic viruses. $^{40}$

The 2009 "swine flu," since then renamed as "novel influenza A (H1N1)" or "pandemic 2009 H1N1 flu," resulted in 18,500 reported laboratory cases and a modeling study estimates that, in total, the $2009 \mathrm{H} 1 \mathrm{~N} 1$ virus caused more than 200,000 influenza-associated deaths due to respiratory and 80,000 deaths due to cardiovascular failure. Importantly, more than $80 \%$ of these lethal cases affected a young population ( $<65$ years). ${ }^{41}$ Contrary to the 1918 virus, the 2009 strain seems to be able to suppress the early innate host immune response which may contribute to a high transmission rate and pathogenicity. ${ }^{42}$

\section{Viral Adaptations Needed for Host Switch and Determinants of Pathogenicity}

To successfully adapt to humans as a new host-either via the direct transmission from birds to humans or a possible further adaptation process in swine-IAVs need to ensure efficient replication and interspecies transmission. Contrary to birds, where IAV replicates in the gastrointestinal epithelia, the primary target cells of IAV in humans as well as in pigs are found in the epithelium of the respiratory tract. Consequently, a successful adaption to the human host requires mutations in the viral replication machinery.

The first step of IAV replication in the human host is the cell attachment, when the virion binds via the viral surface protein HA to sialic acids (SAs) expressed on the upper or lower airway or alveolar epithelial cell. While avian epithelia highly express $\alpha 2,3$-linked SA, the $\alpha 2,6$-linked SA is predominant in the human trachea. After attachment, virions enter the endosomal pathway. ${ }^{43}$ Subsequently, an HA-induced fusion of viral and endosomal membrane is followed by the dissociation of the viral ribonucleoprotein complex (vRNP) consisting of viral RNA, the polymerase complex (viral 
proteins PA, PB1, and PB2), and the viral nucleoprotein (NP), from the M1 protein. ${ }^{44}$ Interestingly, avian and mammalian IAVs show different $\mathrm{pH}$ optima for this HA-mediated membrane fusion, and the respective mutations in the HA protein (amino acids N104D and T115I) have been associated with the capacity to sufficiently release the viral genetic information into the host cell. ${ }^{45,46}$ In the next step, the vRNP is trafficked from the cytosol toward the nucleus. This import is mediated by the cellular importin- $\alpha 7$ in the mammalian system and importin- $\alpha 3$ in the avian host, ${ }^{47-49}$ and the switch in usage of importin isoforms depends on both NP and PB2. ${ }^{49}$ Within the nucleus, the negative-oriented viral $(\mathrm{v}) \mathrm{RNA}$ is transcribed into messenger $(\mathrm{m}) \mathrm{RNA}$, giving rise to new viral proteins by the cellular translation machinery, as well as positiveoriented copy (c)RNA and high amounts of newly transcribed negative-sense vRNA. Herein, the avian polymerase is adapted to working temperature of $41^{\circ} \mathrm{C}$ as found in the avian gastrointestinal tract, whereas in human strains, mutations at position 627 in the PB2 gene are thought to contribute to the tolerance toward lower temperatures found in the human lung. ${ }^{50}$ Virus assembly takes places at the apical cell membrane, where viral proteins and newly formed RNPs accumulate at lipid raft domains, resulting in budding, scission, and release of newly formed virions. ${ }^{51}$ During release, cleavage from cell surface expressed SA by the viral NA is essential to prevent clumping and retention of virions. NA has to switch from cleaving $\alpha 2,3$ - to $\alpha 2,6$-bound SA when introduced into the human host. ${ }^{52,53}$ Furthermore, NA activity has been shown to be temperature- as well as pH-dependent, and multiple alterations promote optimal performance in the human respiratory tract. ${ }^{53,54}$

Especially with regard to pandemic preparedness, an important task is to evaluate the occurrence of virus variants with increased pathogenicity. These IAV variants often show enhanced replication properties or means of immune evasion, some of which will be highlighted here (for a more detailed review, see Baigent and McCauley ${ }^{53}$ as well as Tscherne and García-Sastre ${ }^{55}$ ). Many mutations enhancing replication efficiency can be found in the polymerase complex (reviewed in Mänz et $\mathrm{al}^{56}$ ); most prominent is the E627K substitution in the PB2 gene that is suggested to stabilize the interaction with the NP, to enhance replication rates and to induce higher pathogenicity in the 1918, 1957, and 1968 pandemic IAV. ${ }^{57,58}$ It is found in $32 \%$ of circulating H5N1 variants as well as H7N9 isolates. ${ }^{59-61}$ An important contributor to effective viral spread is the viral nonstructural NS1 protein that plays a major role in limiting the host innate immune response. ${ }^{62,63}$ It prevents viral RNA recognition by the innate system and thus blocks the production of antiviral type I interferons (IFNs) by influenza-infected epithelial cells. ${ }^{64}$ Additionally, NS1 inhibits downstream signaling of protein kinase $\mathrm{R}$ (PKR), downregulates the IFN-receptor, and deregulates processing of cellular mRNA. ${ }^{64}$ Viruses with reduced or lacking NS1 activity are substantially compromised in pathogenicity. ${ }^{65,66}$ Another major determinant of influenza virus pathogenicity is the viral HA. Highly pathogenic avian influenza (HPAI), in contrast to seasonal human IAV and low pathogenic avian influenza strains, bear a multi- basic amino acid motif in the HA cleavage site, which promotes HA cleavage by a higher variety of proteases. ${ }^{3,67} \mathrm{HPAI}-$ induced disease is therefore related to increased disease severity and higher mortality in humans. ${ }^{68,69}$ Additionally, influenza strains newly introduced into the population generally show no or only one to two $\mathrm{N}$-linked glycosylation site (s) in the globular head domain of the HA, whereas seasonal strains acquire more sites to mask their antigenic epitopes $^{70,71}$; over the past 40 years, H3N2 has increased the number of sites of glycosylation in parallel with its pathogenicity decrease. ${ }^{72}$

\section{The Host Response to Influenza-Key Players in Antiviral Defense and in Driving Epithelial Injury}

In patients who succumb to IAV infection, lung autopsies almost always show diffuse alveolar damage, but viral RNA is present in only a subset of patients. ${ }^{73}$ These results and findings from published studies of IAV infection in animals suggest that mortality due to IAV infection may rather result from an overly exaggerated immune response than from uncontrolled viral spread. Several subsets of immune cells were found to contribute to damaging host responses, and some of the underlying molecular mechanisms have been recently defined, providing novel targets for therapeutic intervention $^{64,74}$ (-Fig. 2).

As mentioned earlier, the primary target cells of IAVs are the epithelial cells that mount an anti-inflammatory response upon recognition of pathogen-/danger-associated molecular patterns (PAMPs/DAMPs) by diverse pattern recognition receptors. Viral uncapped 5'-triphosphorylated RNA interacts with RIG-I (RNA helicases retinoic acid-inducible gene-I), leading to a subsequent interaction with MAVS (mitochondria-associated antiviral signaling protein), TRIM25 (tripartite motif-containing protein 25 ), and IPS- 1 (interferon- $\beta$ promoter stimulator-1) and inducing IRF-3 and IRF-7 (interferon regulatory factor)-dependent transcription and translation of types I and III IFNs. ${ }^{75,76}$ Additionally, recognition of viral patterns by PKR activates NF-KB (nuclear factor "kappalight-chain enhancer" of activated B cells) translocation to the nucleus and transcriptional activation of proinflammatory, proapoptotic, and antiviral gene clusters. ${ }^{77-79}$ Other receptors sensing IAV infection include the NLRP3 (NOD-like receptor family, pyrin domain containing 3 ) inflammasome, and also endosomal toll-like receptors (TLR3 and TLR7). ${ }^{80-82}$ Recent evidence suggests that upon viral infection, DAMPs such as high-mobility group box 1 (HMGB1), S100A9, or purine metabolites are crucially involved in influenza disease progression. ${ }^{83,84}$

Similarly to epithelial cells, lung resident macrophages represent a first line of defense and initiate an immune response following viral pattern recognition. They phagocytose viral particles as well as infected apoptotic cells and represent a major source of type I IFNs and further cytokines and chemokines. ${ }^{85,86}$ Thus, resident alveolar macrophages have repeatedly been shown to be crucial for limiting viral spread, morbidity, and mortality after influenza virus 


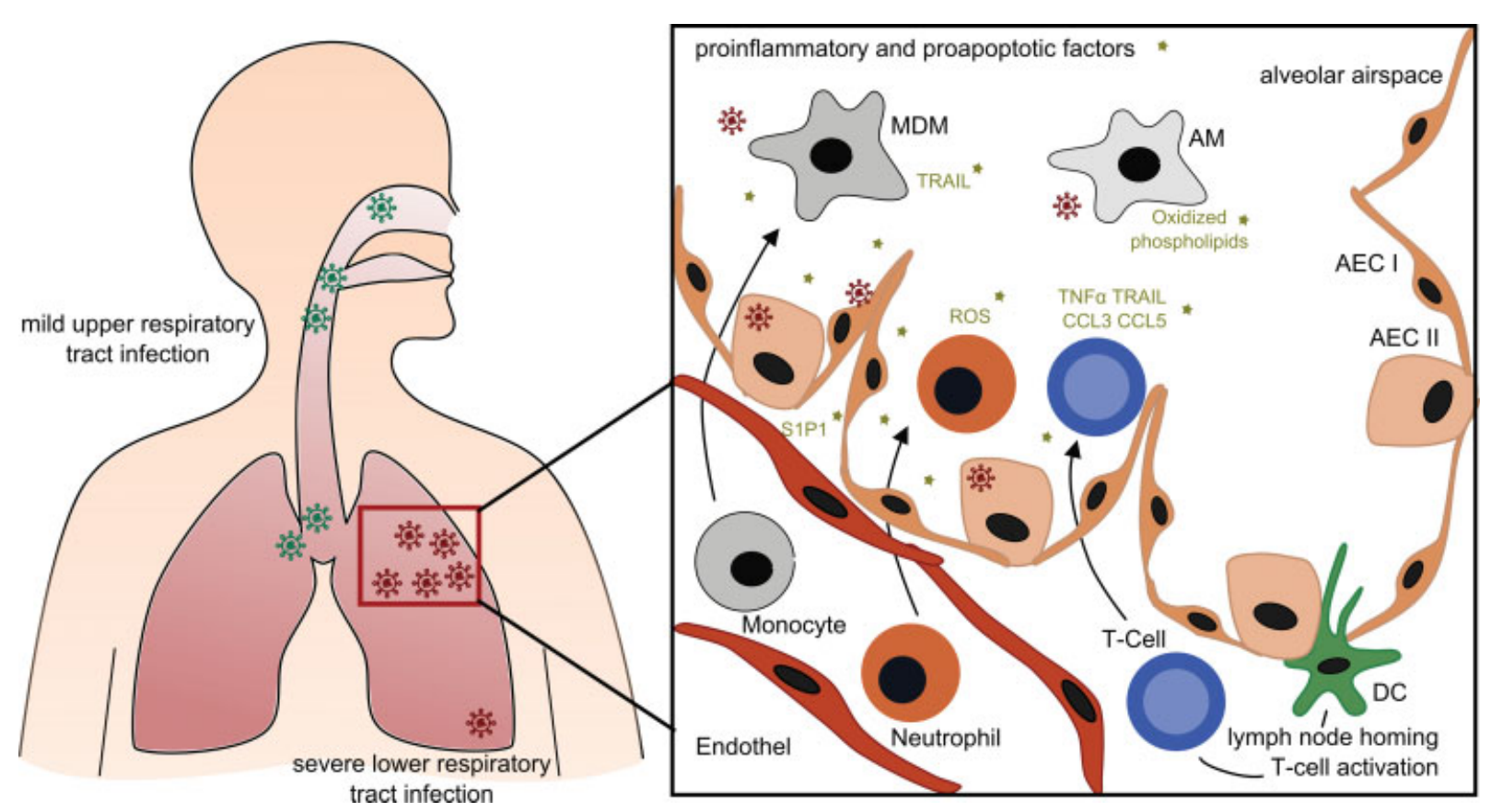

Fig. 2 Key players in influenza A virus (IAV)-induced lung injury. While upper respiratory tract infection results in mild symptomatic IAV infection, severe cases of IAV usually involve spread of the virus to the lower respiratory tract. Here, resident alveolar macrophages (AM) and dendritic cells (DC) sense IAV infection of alveolar epithelial type I (AEC I) and type II (AEC II) cells. Cytokine release and establishment of a proinflammatory milieu in the alveolar lumen lead to recruitment of additional monocyte-derived macrophages (MDM) as well as neutrophils from the blood vessels to the site of infection. DC migration to the lymph nodes further induces generation of antigen-specific T cells into the vessel. An exuberant immune response with massive release of proinflammatory and proapoptotic mediators contributes to IAV-induced lung injury.

infection. ${ }^{87,88}$ At the same time, they initiate innate immune responses as well as adaptive immunity by stimulation of $\mathrm{CD}^{+} \mathrm{T}$ cells that may finally result in immune-related pathologies. For example, oxidized phospholipids produced upon IAV infection in a TLR4-dependent way have been reported to potentiate macrophage cytokine production and are crucially involved in the progression of IAV-induced lung injury. ${ }^{89}$

Neutrophils are highly recruited early after IAV infection into the alveoli and were found to play an ambivalent role in IAV infection. On one hand, depletion of neutrophils early in disease is associated with uncontrolled viral spread and progression from mild to severe influenza-induced illness. ${ }^{88,90,91}$ On the other hand, excessive neutrophilic recruitment, found in highly pathogenic H1N1 and H5N1 infections, ${ }^{40}$ contributes extensively to lung injury. ${ }^{92}$ Already the intercellular migration process of neutrophils recruited in large numbers from the blood vessel into the alveoli requires a structural opening of epithelial junctional complexes, contributing to alveolar barrier disintegration and disease progression to ARDS. ${ }^{93}$ Furthermore, neutrophilic release of various signaling molecules significantly contributes to lung injury, including further cytokines; extracellular proteases; neutrophilic extracellular traps, of which especially histone components have been proven to be injurious in IAV infection ${ }^{92,94}$; and reactive oxygen species. ${ }^{95}$ Besides neutrophilic superoxide dismutase and NADPH oxidase, myeloperoxidase also has been reported to significantly affect the alveolar epithelial barrier integrity. In line, abrogation of CXCL2- or CXCL10-driven neutrophil recruitment during IAV infection improves outcome in preclinical models. ${ }^{96,97}$

Following establishment of a proinflammatory milieu in the infected lung, circulating blood monocytes are recruited to the alveolar lumen and differentiated to monocyte-derived alveolar macrophages and dendritic cells (DCs). ${ }^{98,99}$ The former are, in contrast to the resident alveolar macrophages, directly associated with enhanced severity of influenza-induced injury. ${ }^{100,101}$ They release large amounts of proinflammatory as well as proapoptotic mediators. Among these, especially the type I IFN-induced TRAIL (TNF-related apoptosis inducing ligand) has been shown to induce and sustain collateral lung damage by induction of alveolar epithelial cell apoptosis via its receptor DR5 (death receptor 5). ${ }^{102-105}$ Both inhibition of the recruitment of monocyte-derived alveolar macrophages and abrogation of TRAIL signaling have been found to decrease influenza-induced lung injury, and recent evidence reveals a role of TRAIL in inhibition of edema resolution after IAV-induced lung injury in mice. ${ }^{102,103,106}$

DCs reside in the airway and alveolar epithelium, extending dendrites into the alveolar lumen and thus can be directly infected or sense viral infection via antigen uptake from dying cells. Especially the $\mathrm{CD} 103^{+} \mathrm{DC}$ subset has been reported to be the major subset migrating to the draining lymph nodes in response to activating cytokines such as granulocyte-macrophage colony-stimulating factor $(\mathrm{GM}-\mathrm{CSF})^{107}$ and also in response to NLRP3 inflammasome cytokines, interleukin (IL)-1, and IL-18. ${ }^{108}$ Subsequently activated DC can crosspresent antigen to naive CD4+ and CD8 + T cells, thus priming adaptive immune response. ${ }^{109}$ Interestingly, DC numbers are 
strongly increased in severe H5N1 infection in nonhuman primates $^{110}$ and DCs have been shown to secrete by themselves the NLRP3 inflammasome-dependent mediators IL-1 $\beta$, IL-1 $\alpha$, and IL-18. ${ }^{111,112}$ The T-cell-mediated adaptive immunity to respiratory IAV infection is highly complex and influenced by multiple signaling events derived from epithelial cells, DC, and neutrophils. ${ }^{64}$ Activated CD8+ T cells become cytotoxic effectors able to lyse IAV-antigen presenting infected epithelial cells, and they contribute to the induction of cell apoptosis by production of tumor necrosis factor- $\alpha$ (TNF $\alpha$ ) and TRAIL. ${ }^{113-115}$ Although specific removal of epithelial infected cells by release of cytotoxic granules actively participates to virus clearance, the nonspecific activity of proinflammatory cytokines as TNF $\alpha$, CCL3, and CCL5 released by activated $\mathrm{T}$ cell can additionally impact on noninfected epithelial cells and may thereby enhance lung inflammation and injury. ${ }^{116}$

Additionally, the lung endothelial cells are also affected by influenza virus infection and can impact on epithelial injury in murine influenza models. ${ }^{117}$ They not only mediate monocyte and leukocyte lung intra- and extravasation by expression of adhesion molecules and chemokines such as Eselectin, P-selectin, intercellular adhesion molecule-1 and vascular cell adhesion molecule-1, CXCL9, and CXCL10 118,119 but also release inflammatory mediators such as IL-6 and TNF $\alpha,{ }^{120,121}$ further promoting the proinflammatory milieu during IAV infection. In contrary, endothelial cells are a major source for angiotensin-converting enzyme 2 (ACE2), which downregulates angiotensin 2, and increased serum levels of ACE2 after IAV infection correlates closely with epithelial cell protection and improved outcome after human H5N1 and H7N9 infection. ${ }^{122,123}$ Another important endothelial signaling event orchestrating inflammatory viral lung injury is the sphingosine 1 phosphate pathway. Blockade of the endothelial-produced sphingosine-1-phosphate 1 (S1P1) results in decreased cytokine and chemokine levels correlating with lower mortality rates in influenzainduced lung injury. ${ }^{117,124}$

\section{Clinical Presentation}

Influenza viruses spread in the human population by respiratory droplet transmission. ${ }^{125}$ Influenza infection can be an asymptomatic or mild with an uncomplicated upper respiratory tract illness; in rare cases, however, IAV induces a complicated disease with severe viral pneumonia leading to multiorgan failure or exacerbation of underlying disease conditions. $^{126}$ Seasonal IAVs especially target populations with immunodeficiencies or underlying chronic conditions, such as lung or heart disease. ${ }^{127-130}$

Clinically, an acute onset of symptoms can be observed after 24 to 48 hours of incubation time, correlating with enhanced viral replication. These symptoms constitute the influenza-like illness (ILI) and include headache, cough, myalgias, malaise, chills, and fever that can persist for 2 to 8 days. Pandemic and in a less extent seasonal IAV has furthermore been described to cause gastrointestinal illness with vomiting or diarrhea, especially in children. Severe cases of influenza infection comprise spread of the virus to the alveolar compartment, where both $\alpha 2,6$ - and $\alpha 2,3$-SA are present-the latter highly expressed on type II pneumocytes. ${ }^{131,132}$ Alveolar infection causes extensive diffuse alveolar damage, histologically resembling other forms of ARDS with intra-alveolar hemorrhagic edema accumulation, fibrin deposition, massive infiltration of leukocytes, extensive bronchial and alveolar epithelial cell apoptosis, and formation of hyaline membranes. ${ }^{133}$ Such patients present with progressive respiratory failure, including dyspnea, tachypnea, hypoxia, and radiological signs of diffuse bilateral pneumonia, and later on ARDS with possible fatal outcome. ${ }^{134}$ Frequently, coinfection with colonizing bacteria aggravates the course of illness. Coinfections with Streptococcus pneumoniae and Staphylococcus aureus are the most frequent and have been observed at a high rate during pandemics leading to an increase in pneumonia-associated death. ${ }^{135}$ The autopsy of 68 soldiers who died during the Spanish flu wave revealed evidence of bacterial pneumonia in the lung in most cases. ${ }^{39} \mathrm{~A}$ cohort studies in 14 Australian ICUs demonstrated that during the 2009 influenza season, coinfections were dominant in a previously healthy younger population without comorbidities. ${ }^{136}$ Coinfection with further respiratory viruses such as respiratory syncytial virus aggravates the severity of the disease, ${ }^{137}$ especially in immunocompromised patients. $^{138}$

\section{Intervention Strategies}

Treatment for typical ILI is generally supportive. One major challenge in the treatment of influenza virus infection is early detection, as influenza-specific antiviral therapy is most effective in the beginning of the disease. As first symptoms are not specifically attributable to IAV but more generally to respiratory viral infection, rapid ELISA-based antigen tests eventually combined with PCR-based diagnostics tests are recommended-especially during the influenza season-to allow a fast differentiation from other causes and rapid onset of antiviral treatment. However, WHO guidelines recommend to provide initial treatment against influenza without awaiting delayed laboratory test results. ${ }^{126}$

Currently used antivirals in clinical trials are summarized in - Table 1. The primary antiviral and empiric treatment for mild as well as severe influenza $A$ and $B$ virus infections is administration of the NA inhibitors, recommended by the WHO to be applied as early as possible in all high-risk patients (immunocompromised, severe comorbidities, underlying chronic lung disease, age $<2$ or $>65$ years, morbid obesity, nursing home residents, women who are pregnant or postpartum), and in all patients with signs of severe respiratory disease. Randomized clinical trials have confirmed the efficacy of NA inhibitors to diminish symptom duration and risk of pneumonia complications ${ }^{139}$ and length of treatment or dose may be increased in immunocompromised patients. Currently, all circulating A and B strains are susceptible to approved NA inhibitors; however, previously circulating H1N1 IAV strains have been widely resistant to oseltamivir. ${ }^{140}$ A way to overcome viral resistance may be to combine antiviral drugs with different modes of action in future, ${ }^{141}$ 
Table 1 Current antiviral drugs and novel antivirals in clinical trials

\begin{tabular}{|c|c|c|c|c|}
\hline Name & Trademark & Status & Mechanism of inhibition & Comments \\
\hline Amantadine & Symmetrel & FDA approved (1966) & Steric inhibition of $\mathrm{M} 2$ ion conductance & $\begin{array}{l}\text { Not recommended due to high } \\
\text { prevalence of resistant variants }\end{array}$ \\
\hline Rimantadine & Flumadine & FDA approved (1994) & Steric inhibition of $\mathrm{M} 2$ ion conductance & $\begin{array}{l}\text { Not recommended due to high } \\
\text { prevalence of resistant variants }\end{array}$ \\
\hline Oseltamivir & Tamiflu & FDA approved (1999) & Binding to enzymatic active site of NA & $\begin{array}{l}\text { Approved for patients } \\
\geq 2 \text { wk and older, orally }\end{array}$ \\
\hline Zanamivir & Relenza & FDA approved (1999) & Binding to enzymatic active site of NA & $\begin{array}{l}\text { Approved for patients } \\
\geq 5 \text { y and older, per inhalation }\end{array}$ \\
\hline Peramivir & $\begin{array}{l}\text { Rapivab, } \\
\text { Rapiacta }\end{array}$ & FDA approved (2014) & Binding to enzymatic active site of NA & $\begin{array}{l}\text { Approved for patients } \geq 18 \text { y } \\
\text { and older, intravenously }\end{array}$ \\
\hline Laninamivir & Inavir & $\begin{array}{l}\text { Approved } \\
\text { (Japan, 2010) }\end{array}$ & Binding to enzymatic active site of NA & $\begin{array}{l}\text { Approved for treatment } \\
\text { (2010) and prevention (2013), } \\
\text { per inhalation }\end{array}$ \\
\hline AVI-7100 & & Phase I & $\begin{array}{l}\text { Interference with expression of viral } \\
\mathrm{M} \text { gene segment }\end{array}$ & \\
\hline DAS181-F03 & & Phase I & $\begin{array}{l}\text { Cleavage of sialic acids from } \\
\text { host cell surface }\end{array}$ & \\
\hline Flufirvitide & & Phase I & $\begin{array}{l}\text { Peptide inhibitor binding thus } \\
\text { blocking viral HA }\end{array}$ & \\
\hline Favipiravir & & Phase III & Nucleoside inhibitor targeting PB1 & \\
\hline Nitazoxanide & & Phase III & Blockade of HA maturation & \\
\hline
\end{tabular}

Abbreviations: FDA, Food and Drug Administration; HA, hemagglutinin; NA, neuraminidase. Information used from: www.cdc.gov; www.fda.gov; www.clinicaltrials.gov (September 2015).

and to additionally target host cellular pathways known to be indispensable for viral replication at the virus-host interface.

For patients presenting with influenza-associated respiratory failure, NA treatment is highly recommended and was found to be effective in terms of outcome even when applied later than 48 hours post-symptom onset. NA inhibitors are frequently applied through the intravenous route in critical care patients. ${ }^{142}$ Complementary to antivirals, supportive treatment is necessary. ${ }^{143}$ These measures include standard care for ARDS, ${ }^{144,145}$ and extracorporal membrane oxygenation protocols were found to be beneficial, ${ }^{146}$ whereas treatment by anti-inflammatory strategies such as systemic corticosteroid treatment is not recommended to date. ${ }^{147,148}$ As bacterial coinfections constitute a major complication which increases the severity of the disease and worsens outcome, patients with influenza-associated ARDS should be carefully monitored to start empiric antibiotic treatment as early as possible. Jain et al suggested that patients hospitalized with suspected influenza and lung infiltrates on chest radiography should receive early and aggressive treatment with both antibiotics and influenza antiviral agents. ${ }^{149}$

\section{At-Risk Populations}

Influenza especially targets humans with altered immune responses and is generally associated with a U-shaped mortality curve, except for both $1918^{38}$ and 2009 pandemics which display $\mathrm{W}$-shape curves. ${ }^{150}$ This means that high death rates are observed in children younger than 2 years and elderly persons older than 65 years in seasonal influenza infections, whereas young adults show high mortality rates during pandemics, where the elderly may be protected to some extent due to preexisting immunity. Additional risk factors or comorbidities enhancing the likeliness to develop severe influenza-induced complications comprise age, chronic respiratory, renal, hematologic, neurologic or cardiovascular disease, diabetes, obesity, immunosuppression/deficiency, and pregnancy/postpartum period as many clinical studies on hospitalized 2009 influenza have demonstrated. ${ }^{128-130,151-153}$ A global pooled analysis on 70,000 hospitalized 2009 influenza patients indicate that children ( $<15$ years) present a higher risk of being admitted to hospital, whereas older adults ( $>50$ years) display higher mortality rates. Furthermore, morbid obesity seems to be associated with the risk of ICU hospitalization and lethal outcome. $^{130}$ Immunocompromised persons suffer from a more severe disease and are more likely to develop drugresistance mutations. ${ }^{154,155}$ Numerous clinical studies especially on 2009 pandemic cases ${ }^{156,157}$ and WHO or CDC recommendations ${ }^{158,159}$ identify pregnancy as comorbidity factor for influenza and advise general vaccination of this risk population. Pregnant women are more susceptible for infection with influenza, develop a more severe disease associated with worse pregnancy outcomes, and show higher risk of ICU admission and increased mortality. Biological reasons for this predisposition are not yet defined, but changes in immune responses, particularly in antiviral responses, ${ }^{160}$ associated with pregnancy are involved and the fetus-associated 
complications are probably essentially due to maternal fever. ${ }^{161}$ As well as maternal protection, vaccination also protects newborns and infants, another risk population, for which vaccination is recommended from 6 months of age in the United States and in the European Union (EU), with the latter mostly limited to infants with increased risk of exposure. $^{162}$

Importantly, with respect to development of personalized therapies, recent studies have highlighted a link between host genetic predisposition and susceptibility to influenza viruses. Albright and colleagues have observed a hereditary contribution in lethal cases of influenza in Utah. ${ }^{163}$ As IFN-dependent proteins and cytokines are known to be important for host defense against viruses, genome-wide association studies (GWAS) have focused on association between specific polymorphisms and susceptibility to influenza. The IFN-inducible transmembrane protein 3 (IFITM3) plays clearly an important role in host defense against $\mathrm{H} 1 \mathrm{~N} 1{ }^{164}$ and $\mathrm{H} 7 \mathrm{~N} 9,{ }^{165}$ but the association between its single-nucleotide polymorphism rs12252 and influenza susceptibility remains a matter of controversy. ${ }^{166,167}$ Recently, deficiency in IRF7 has been associated with a severe case of influenza infection. ${ }^{168} \mathrm{Mu}-$ tations in the IL1A and IL1B genes (coding for interleukins 1- $\alpha$ and $-\beta$ ), in the genes encoding the protease TMPRSS2 (transmembrane protease, serin 2 , mediating viral HA cleavage upon infection), or galectin- $1^{169-171}$ can furthermore impact the host susceptibility to H1N1 or H7N9.

\section{Vaccination}

Considering the aforementioned obstacles present for efficient and timely treatment of severe influenza infections, preventive vaccination is a key tool to diminish influenza morbidity as well as socioeconomic burden. ${ }^{172}$ Even if national guidelines for influenza virus vaccination vary, vaccination is generally recommended not only to high-risk patients with preexisting comorbidities or high risk of exposure but also to the whole population (6 months of age or older) to not only limit the individual risk of infection but also to improve herd immunity and the likeliness for reassortment events. ${ }^{173}$ As influenza virus strains gradually change between seasons, the composition of the vaccine is updated yearly based on recommendations of the WHO that monitors the global influenza virus occurrence. The currently approved vaccinations are either based on egg- or cell culture-grown inactivated subunit vaccines that are administered intramuscularly, or live, attenuated influenza viruses that are used for intranasal administration in children in the United States and Europe. ${ }^{174}$ The inactivated trivalent or quadrivalent vaccination preparations contain antigens of two IAV strains (currently a descendant of the pandemic $\mathrm{H} 1 \mathrm{~N} 1$ and a circulating H3N2 strain) and of one or two influenza B virus strains (Yamagata and Victoria line), respectively, and mainly trigger an immunoglobulin $G$ ( $\operatorname{IgG}$ ) serum response. ${ }^{175}$ This IgGmediated protection can be suboptimal especially in cases of strong divergence between the antigens used for vaccination and those of the currently circulating seasonal influenza strains, when prediction is suboptimal. To minimize reduced efficacy, efforts are taken to develop vaccines that elicit cross protection against several strains and are directed against a conserved HA stem region. ${ }^{176-178}$ Live, attenuated vaccine strains are usually generated on an $\mathrm{H} 2 \mathrm{~N} 2$ backbone and reassorted with the WHO-recommended strains to carry the current $\mathrm{HA}$ and NA genetic information and surface protein expression adapted to growth at $25^{\circ} \mathrm{C}$, thus limiting spread in the human host. ${ }^{179}$ They elicit a stronger immune response including IgG and IgA production as well as T-cell memory, but are considered less safe, as they bear the potential risk of reversion to a nonattenuated form and a possible reassortment platform for circulating virus stains. ${ }^{180}$ Therefore, efforts are made to improve safety of live, attenuated vaccines, for example, by engineering variants unable to circumvent the antiviral IFN response by deleting or inserting a truncated NS1 protein. ${ }^{174}$

\section{Novel Therapeutic Approaches}

In the light of the growing prevalence of drug-resistant IAV strains, substantial efforts are taken to establish new strategies to limit viral replication and improve outcomes of IAV infection, some of which are currently tested for human application in clinical trials (-Table $\mathbf{1}$ ). One class of drugs comprises classical antiviral agents, directly targeting viral proteins and their function. Neutralizing antibodies against both the HA and the M2 are tested that are active against a broader range of influenza strains. ${ }^{181,182}$ The viral HA is further targeted by decoy receptors or SA-containing inhibitors as well as carbohydrate-binding drugs, which block the HA by binding to its glycosylation sites and thus prevent cell adsorption (i.e., cyanovirin-N 56). ${ }^{183}$ Favipiravir is a nucleoside inhibitor currently evaluated in phase III trials that blocks the activity of the viral polymerase complex and revealed very limited development of resistant IAV. ${ }^{184,185}$ Moreover, classical SA synthetic analogues that act similarly as oseltamivir and zanamivir have been developed resulting in admission of laninamivir and peramivir recently. ${ }^{186-188}$ Other strategies to directly target viral components include the use of small interfering RNA ${ }^{189,190}$ and small molecule inhibitors. ${ }^{191}$ Moreover, combination therapies using different antiviral drugs are currently studied in detail and have shown efficacy in limiting IAV replication.

Another class of novel antiviral drugs influences host cell proteins or signaling pathways necessary for viral infection or replication. DAS181 (Fludase) abrogates HA adsorption to the host cell by cleavage of SA from the host cell surface. ${ }^{192-194} \mathrm{HA}$ is further targeted by agents preventing correct posttranslational processing of the transmembrane protein (Nitazoxanide), as well as by blocking cleavage of HA by the internal proteases HAT and TMPRSS2 (Aprotinin). ${ }^{192,195}$ Another approach is the inhibition of the transcription factor NF-kB that has been proven to be activated upon influenza infection and to be supportive for virus replication. ${ }^{196}$ Given that NF-KB inhibition resulted in reduced viral replication, less inflammation, and improved outcome in preclinical models, an inhaled compound, L-lysine acetylsalicylate glycine (LASAG), has been tested in phase II trials. ${ }^{197}$ Other strategies interrupt 
virus replication through specific modulation of lipid raft domains (Viperin), ${ }^{198}$ the MAP kinase pathway, pyridine metabolism, protectin D expression, and even IFN modulation, ${ }^{191,199}$ where the latter is either enhanced early in IAV infection or suppressed by neutralizing antibodies late in disease progression. ${ }^{200}$ Further strategies are aimed to modulate an unbalanced, overshooting inflammatory response during virus-induced lung injury, to promote pulmonary host defense and to drive repair of the damaged epithelium after virus clearance. GM-CSF is an important modulator of macrophage and DC-mediated antiviral immunity, and also plays a major role in the repair of the alveolar epithelium. ${ }^{201-203}$ As such, we suggested that local administration of GM-CSF to patients with pneumonia- and IAV-induced ARDS will improve host defense, oxygenation, and outcome, ${ }^{204}$ and a placebo-controlled, double-blind, randomized multicenter phase II trial on inhaled GM-CSF for treatment of ARDS induced by bacterial or viral pneumonia has been launched. Such host-modulating therapies are envisioned to be combined with antivirals in future to improve outcome of influenza-induced respiratory failure. ${ }^{141}$

Finally, future therapeutic options are stem cell-based approaches. Interestingly, preclinical studies have shown the beneficial effects of the application of bone marrowderived mesenchymal stromal cells (MSCs) which possess immunomodulatory and regenerative properties ${ }^{205}$ for the treatment of acute lung injury, ${ }^{206}$ and MSCs are currently tested as therapy for human ARDS. ${ }^{207}$ Even if the potential of MSC has not been studied in preclinical models of influenza pneumonia so far, cell therapy-applied either systemically or locally into the injured lung-may constitute an innovative approach to treat IAV-induced ARDS patients. ${ }^{208}$ Moreover, endogenous epithelial stem/progenitor cells in the murine lung have been recently defined and were found to repopulate distal lung epithelium and therefore to actively participate to the repair phase after influenza-induced injury through activation of a p63/krt5 regeneration program. ${ }^{209,210}$ Our own data reveal that these regeneration pathways are induced and particularly modulated by influenza viruses during infection of the stem cell niche ${ }^{211}$, highlighting endogenous stem cells and their mediators as novel putative targets to improve lung regeneration after severe viral damage.

\section{Conclusion}

Taken together, IAV-induced lung injury still shows a major impact on human health, but substantial work is invested in the monitoring and the prevention of IAV-induced disease as well as in promising concepts to improve outcomes of IAVinduced ARDS. A key challenge in influenza research is to design innovative host-based therapies able to boost antiviral immunity and to improve lung regeneration. Translational approaches should be focused on better understanding of viral-host interactions as well as immunopathogenic mechanisms to define signaling pathways on a molecular basis amenable to specific targeting. Meanwhile, defining host susceptibility factors will accelerate recognition and treatment of a new category of risk patients and also promote the discovery of novel strategies for personalized therapies. It will also be necessary to understand the mechanisms underlying the increased susceptibility to bacterial outgrowth associated with influenza infection, to reduce the prevalence of secondary infections with increased morbidities. Finally, ongoing research on stem cell-based therapies, including injury- or pathogen-specific programming of these cells prior to application to improve their particular modes of action in different forms of acute lung injury, reveals promising results which will likely be the basic of future therapies against ARDS.

\section{Acknowledgments}

This work was supported by the German Research Foundation (SFB1021 C05, SFB-TR84 B2, EXC147), by the German Federal Ministry of Research and Education ("FluResearchNet" grant no. 01 KI 1006M), by the German Center for Lung Research (DZL), and by the German Center for Infection Research (DZIF).

\section{References}

1 Schmolke M, García-Sastre A. Evasion of innate and adaptive immune responses by influenza A virus. Cell Microbiol 2010; 12(7):873-880

2 Vossen MT, Westerhout EM, Söderberg-Nauclér C, Wiertz EJ. Viral immune evasion: a masterpiece of evolution. Immunogenetics 2002;54(8):527-542

3 Abdel-Ghafar AN, Chotpitayasunondh T, Gao Z, et al; Writing Committee of the Second World Health Organization Consultation on Clinical Aspects of Human Infection with Avian Influenza A (H5N1) Virus. Update on avian influenza A (H5N1) virus infection in humans. N Engl J Med 2008;358(3):261-273

4 Ungchusak K, Auewarakul P, Dowell SF, et al. Probable person-toperson transmission of avian influenza A (H5N1). N Engl J Med 2005;352(4):333-340

5 Wu Y, Wu Y, Tefsen B, Shi Y, Gao GF. Bat-derived influenza-like viruses H17N10 and H18N11. Trends Microbiol 2014;22(4): 183-191

6 García-Sastre A. The neuraminidase of bat influenza viruses is not a neuraminidase. Proc Natl Acad Sci U S A 2012;109(46): 18635-18636

7 Lowen AC, Mubareka S, Steel J, Palese P. Influenza virus transmission is dependent on relative humidity and temperature. PLoS Pathog 2007;3(10):1470-1476

8 Bedford T, Riley S, Barr IG, et al. Global circulation patterns of seasonal influenza viruses vary with antigenic drift. Nature 2015; 523(7559):217-220

9 Rambaut A, Pybus OG, Nelson MI, Viboud C, Taubenberger JK, Holmes EC. The genomic and epidemiological dynamics of human influenza A virus. Nature 2008;453(7195):615-619

10 World Health Organization Fact Sheet on Influenza; 2014. Available at: http://www.who.int/mediacentre/factsheets/ fs211/en/. Accessed August 18, 2015

11 Ortiz JR, Neuzil KM, Rue TC, et al. Population-based incidence estimates of influenza-associated respiratory failure hospitalizations, 2003 to 2009. Am J Respir Crit Care Med 2013;188(6): 710-715

12 Molinari NA, Ortega-Sanchez IR, Messonnier ML, et al. The annual impact of seasonal influenza in the US: measuring disease burden and costs. Vaccine 2007;25(27):5086-5096

13 Cox NJ, Subbarao K. Global epidemiology of influenza: past and present. Annu Rev Med 2000;51:407-421 
14 Simonsen L, Clarke MJ, Schonberger LB, Arden NH, Cox NJ, Fukuda K. Pandemic versus epidemic influenza mortality: a pattern of changing age distribution. J Infect Dis 1998;178(1):53-60

15 Taubenberger JK. The origin and virulence of the 1918 "Spanish" influenza virus. Proc Am Philos Soc 2006;150(1):86-112

16 Miller MA, Viboud C, Balinska M, Simonsen L. The signature features of influenza pandemics-implications for policy. N Engl J Med 2009;360(25):2595-2598

17 Libster R, Coviello S, Cavalieri ML, et al. Pediatric hospitalizations due to influenza in 2010 in Argentina. N Engl J Med 2010; 363(25):2472-2473

18 Tanner WD, Toth DJ, Gundlapalli AV. The pandemic potential of avian influenza $A(H 7 N 9)$ virus: a review. Epidemiol Infect 2015; 143(16):3359-3374

19 Pappaioanou M, Gramer M. Lessons from pandemic H1N1 2009 to improve prevention, detection, and response to influenza pandemics from a One Health perspective. ILAR J 2010;51(3): 268-280

20 Goldstein T, Mena I, Anthony SJ, et al. Pandemic H1N1 influenza isolated from free-ranging Northern Elephant Seals in 2010 off the central California coast. PLoS ONE 2013;8(5):e62259

21 Parrish CR, Murcia PR, Holmes EC. Influenza virus reservoirs and intermediate hosts: dogs, horses, and new possibilities for influenza virus exposure of humans. J Virol 2015;89(6):2990-2994

22 Uyeki TM, Cox NJ. Global concerns regarding novel influenza A (H7N9) virus infections. N Engl J Med 2013;368(20):1862-1864

23 Simon PF, McCorrister S, Hu P, et al. Highly pathogenic H5N1 and novel H7N9 influenza A viruses induce more profound proteomic host responses than seasonal and pandemic H1N1 strains. J Proteome Res 2015;14(11):4511-4523

24 H5N1 Avian Flu (H5N1 Bird Flu). Available at: http://wwwflugov/ about_the_flu/h5n1/indexhtml. Accessed August 21, 2015

25 WHO. Cumulative number of confirmed human cases for avian influenza A(H5N1) reported to WHO 2003-2015. Available at: http://www.who.int/influenza/human_animal_interface/ EN_GIP_20150904cumulativeNumberH5N1cases.pdf. Accessed August 21, 2015

26 Areechokchai D, Jiraphongsa C, Laosiritaworn Y, Hanshaoworakul W, O'Reilly M; Centers for Disease Control and Prevention (CDC). Investigation of avian influenza (H5N1) outbreak in humansThailand, 2004. MMWR Suppl 2006;55(Suppl 1):3-6

27 Chen Y, Liang W, Yang S, et al. Human infections with the emerging avian influenza A H7N9 virus from wet market poultry: clinical analysis and characterisation of viral genome. Lancet 2013;381(9881):1916-1925

28 WHO. Who Risk Assessment of Human infections with avian influenza A (H7N9) Virus. Available at: http://www.who.int/ influenza/human_animal_interface/influenza_h7n9/RiskAssessment_H7N9_23Feb20115.pdf?ua=1. Accessed August 21, 2015

29 Xiong X, Martin SR, Haire LF, et al. Receptor binding by an H7N9 influenza virus from humans. Nature 2013;499(7459):496-499

30 Chan MC, Chan RW, Chan LL, et al. Tropism and innate host responses of a novel avian influenza A H7N9 virus: an analysis of ex-vivo and in-vitro cultures of the human respiratory tract. Lancet Respir Med 2013;1(7):534-542

31 ItoT, Couceiro JN, Kelm S, et al. Molecular basis for the generation in pigs of influenza A viruses with pandemic potential. J Virol 1998;72(9):7367-7373

32 Janke BH. Influenza A virus infections in swine: pathogenesis and diagnosis. Vet Pathol 2014;51(2):410-426

33 Trock SC, Burke SA, Cox NJ. Development of framework for assessing influenza virus pandemic risk. Emerg Infect Dis 2015; 21(8):1372-1378

34 Valleron AJ, Cori A, Valtat S, Meurisse S, Carrat F, Boëlle PY. Transmissibility and geographic spread of the 1889 influenza pandemic. Proc Natl Acad Sci U S A 2010;107(19):8778-8781
35 Trotter Y Jr, Dunn FL, Drachman RH, Henderson DA, Pizzi M, Langmuir AD. Asian influenza in the United States, 1957-1958. Am J Hyg 1959;70(1):34-50

$36 \mathrm{Xu} \mathrm{R}$, McBride R, Paulson JC, Basler CF, Wilson IA. Structure, receptor binding, and antigenicity of influenza virus hemagglutinins from the 1957 H2N2 pandemic. J Virol 2010;84(4): 1715-1721

37 Lindsay MI Jr, Herrmann EC Jr, Morrow GW Jr, Brown AL Jr. Hong Kong influenza: clinical, microbiologic, and pathologic features in 127 cases. JAMA 1970;214(10):1825-1832

38 Taubenberger JK, Morens DM. 1918 Influenza: the mother of all pandemics. Emerg Infect Dis 2006;12(1):15-22

39 Sheng ZM, Chertow DS, Ambroggio X, et al. Autopsy series of 68 cases dying before and during the 1918 influenza pandemic peak. Proc Natl Acad Sci U S A 2011;108(39):16416-16421

40 Perrone LA, Plowden JK, García-Sastre A, Katz JM, Tumpey TM. H5N1 and 1918 pandemic influenza virus infection results in early and excessive infiltration of macrophages and neutrophils in the lungs of mice. PLoS Pathog 2008;4(8):e1000115

41 Dawood FS, Iuliano AD, Reed C, et al. Estimated global mortality associated with the first 12 months of 2009 pandemic influenza $A$ H1N1 virus circulation: a modelling study. Lancet Infect Dis 2012; 12(9):687-695

42 Mukherjee S, Vipat VC, Mishra AC, Pawar SD, Chakrabarti AK. Pandemic (H1N1) 2009 influenza virus induces weaker host immune responses in vitro: a possible mechanism of high transmissibility. Virol J 2011;8:140

43 Rust MJ, Lakadamyali M, Zhang F, Zhuang X. Assembly of endocytic machinery around individual influenza viruses during viral entry. Nat Struct Mol Biol 2004;11(6):567-573

44 Pinto LH, Lamb RA. The M2 proton channels of influenza A and B viruses. J Biol Chem 2006;281(14):8997-9000

45 Mair CM, Ludwig K, Herrmann A, Sieben C. Receptor binding and $\mathrm{pH}$ stability - how influenza A virus hemagglutinin affects host-specific virus infection. Biochim Biophys Acta 2014; 1838(4):1153-1168

46 Zaraket H, Bridges OA, Russell CJ. The $\mathrm{pH}$ of activation of the hemagglutinin protein regulates $\mathrm{H} 5 \mathrm{~N} 1$ influenza virus replication and pathogenesis in mice. J Virol 2013;87(9):4826-4834

47 Resa-Infante P, Thieme R, Ernst T, et al. Importin- $\alpha 7$ is required for enhanced influenza A virus replication in the alveolar epithelium and severe lung damage in mice. J Virol 2014;88(14): 8166-8179

48 Gabriel G, Klingel K, Otte A, et al. Differential use of importin- $\alpha$ isoforms governs cell tropism and host adaptation of influenza virus. Nat Commun 2011;2:156

49 Gabriel G, Herwig A, Klenk HD. Interaction of polymerase subunit PB2 and NP with importin alpha1 is a determinant of host range of influenza A virus. PLoS Pathog 2008;4(2):e11

50 Massin P, van der Werf S, Naffakh N. Residue 627 of PB2 is a determinant of cold sensitivity in RNA replication of avian influenza viruses. J Virol 2001;75(11):5398-5404

51 Rossman JS, Lamb RA. Influenza virus assembly and budding. Virology 2011;411(2):229-236

52 Wagner R, Matrosovich M, Klenk HD. Functional balance between haemagglutinin and neuraminidase in influenza virus infections. Rev Med Virol 2002;12(3):159-166

53 Baigent SJ, McCauley JW. Influenza type A in humans, mammals and birds: determinants of virus virulence, host-range and interspecies transmission. BioEssays 2003;25(7):657-671

54 Scull MA, Gillim-Ross L, Santos C, et al. Avian Influenza virus glycoproteins restrict virus replication and spread through human airway epithelium at temperatures of the proximal airways. PLoS Pathog 2009;5(5):e1000424

55 Tscherne DM, García-Sastre A. Virulence determinants of pandemic influenza viruses. J Clin Invest 2011;121(1):6-13 
56 Mänz B, Schwemmle M, Brunotte L. Adaptation of avian influenza A virus polymerase in mammals to overcome the host species barrier. J Virol 2013;87(13):7200-7209

57 Scholtissek C, Rohde W, Von Hoyningen V, Rott R. On the origin of the human influenza virus subtypes H2N2 and H3N2. Virology 1978;87(1):13-20

58 Taubenberger JK, Reid AH, Lourens RM, Wang R, Jin G, Fanning TG. Characterization of the 1918 influenza virus polymerase genes. Nature 2005;437(7060):889-893

59 Liu Q Lu L, Sun Z, Chen GW, Wen Y, Jiang S. Genomic signature and protein sequence analysis of a novel influenza $A$ (H7N9) virus that causes an outbreak in humans in China. Microbes Infect 2013;15(6-7):432-439

60 Long JS, Howard WA, Núñez A, et al. The effect of the PB2 mutation $627 \mathrm{~K}$ on highly pathogenic $\mathrm{H} 5 \mathrm{~N} 1$ avian influenza virus is dependent on the virus lineage.J Virol 2013;87(18):9983-9996

61 Salomon R, Franks J, Govorkova EA, et al. The polymerase complex genes contribute to the high virulence of the human H5N1 influenza virus isolate A/Vietnam/1203/04. J Exp Med 2006; 203(3):689-697

62 Mukherjee S, Majumdar S, Vipat VC, Mishra AC, Chakrabarti AK. Non structural protein of avian influenza A (H11N1) virus is a weaker suppressor of immune responses but capable of inducing apoptosis in host cells. Virol J 2012;9:149

63 Munier S, Larcher T, Cormier-Aline F, et al. A genetically engineered waterfowl influenza virus with a deletion in the stalk of the neuraminidase has increased virulence for chickens. J Virol 2010;84(2):940-952

64 Herold S, Becker C, Ridge KM, Budinger GR. Influenza virusinduced lung injury: pathogenesis and implications for treatment. Eur Respir J 2015;45(5):1463-1478

65 Solórzano A, Webby RJ, Lager KM, Janke BH, García-Sastre A, Richt JA. Mutations in the NS1 protein of swine influenza virus impair anti-interferon activity and confer attenuation in pigs. J Virol 2005;79(12):7535-7543

66 Wang $\mathrm{X}$, Li M, Zheng $\mathrm{H}$, et al. Influenza A virus NS1 protein prevents activation of NF-kappaB and induction of alpha/beta interferon. J Virol 2000;74(24):11566-11573

67 Fouchier RA, Schneeberger PM, Rozendaal FW, et al. Avian influenza A virus (H7N7) associated with human conjunctivitis and a fatal case of acute respiratory distress syndrome. Proc Natl Acad Sci U S A 2004;101(5):1356-1361

68 Steinhauer DA. Role of hemagglutinin cleavage for the pathogenicity of influenza virus. Virology 1999;258(1):1-20

69 Klenk HD, Garten W. Host cell proteases controlling virus pathogenicity. Trends Microbiol 1994;2(2):39-43

70 Tate MD, Job ER, Deng YM, Gunalan V, Maurer-Stroh S, Reading PC. Playing hide and seek: how glycosylation of the influenza virus hemagglutinin can modulate the immune response to infection. Viruses 2014;6(3):1294-1316

71 Kim JI, Park MS. N-linked glycosylation in the hemagglutinin of influenza A viruses. Yonsei Med J 2012;53(5):886-893

72 Vigerust DJ, Ulett KB, Boyd KL, Madsen J, Hawgood S, McCullers JA. N-linked glycosylation attenuates H3N2 influenza viruses. J Virol 2007;81(16):8593-8600

73 Bautista E, Chotpitayasunondh T, Gao Z, et al; Writing Committee of the WHO Consultation on Clinical Aspects of Pandemic (H1N1) 2009 Influenza. Clinical aspects of pandemic 2009 influenza A (H1N1) virus infection. N Engl J Med 2010;362(18):1708-1719

74 Short KR, Kroeze EJ, Fouchier RA, Kuiken T. Pathogenesis of influenza-induced acute respiratory distress syndrome. Lancet Infect Dis 2014;14(1):57-69

75 Gack MU, Shin YC, Joo CH, et al. TRIM25 RING-finger E3 ubiquitin ligase is essential for RIG-I-mediated antiviral activity. Nature 2007;446(7138):916-920

76 Opitz B, Rejaibi A, Dauber B, et al. IFNbeta induction by influenza A virus is mediated by RIG-I which is regulated by the viral NS1 protein. Cell Microbiol 2007;9(4):930-938
77 Clemens MJ, Elia A. The double-stranded RNA-dependent protein kinase PKR: structure and function. J Interferon Cytokine Res 1997;17(9):503-524

78 Gil J, Esteban M. Induction of apoptosis by the dsRNA-dependent protein kinase (PKR): mechanism of action. Apoptosis 2000;5(2): 107-114

79 Kumar A, Haque J, Lacoste J, Hiscott J, Williams BR. Doublestranded RNA-dependent protein kinase activates transcription factor NF-kappa B by phosphorylating I kappa B. Proc Natl Acad Sci U S A 1994;91(14):6288-6292

80 Perona-Wright G, Kohlmeier JE, Bassity E, et al. Persistent loss of IL-27 responsiveness in CD8+ memory T cells abrogates IL-10 expression in a recall response. Proc Natl Acad Sci U S A 2012; 109(45):18535-18540

81 Sun J, Dodd H, Moser EK, Sharma R, Braciale TJ. CD4+ T cell help and innate-derived IL-27 induce Blimp-1-dependent IL-10 production by antiviral CTLs. Nat Immunol 2011;12(4):327-334

82 Sun J, Madan R, Karp CL, Braciale TJ. Effector T cells control lung inflammation during acute influenza virus infection by producing IL-10. Nat Med 2009;15(3):277-284

83 Ito Y, Torii Y, Ohta R, et al. Increased levels of cytokines and highmobility group box 1 are associated with the development of severe pneumonia, but not acute encephalopathy, in 2009 H1N1 influenza-infected children. Cytokine 2011;56(2):180-187

84 Tsai SY, Segovia JA, Chang TH, et al. DAMP molecule S100A9 acts as a molecular pattern to enhance inflammation during influenza A virus infection: role of DDX21-TRIF-TLR4-MyD88 pathway. PLoS Pathog 2014;10(1):e1003848

85 Kumagai Y, Takeuchi O, Kato H, et al. Alveolar macrophages are the primary interferon-alpha producer in pulmonary infection with RNA viruses. Immunity 2007;27(2):240-252

86 Wang J, Nikrad MP, Travanty EA, et al. Innate immune response of human alveolar macrophages during influenza A infection. PLoS ONE 2012;7(3):e29879

$87 \mathrm{Kim} \mathrm{HM}$, Lee YW, Lee KJ, et al. Alveolar macrophages are indispensable for controlling influenza viruses in lungs of pigs. J Virol 2008;82(9):4265-4274

88 Tumpey TM, García-Sastre A, Taubenberger JK, et al. Pathogenicity of influenza viruses with genes from the 1918 pandemic virus: functional roles of alveolar macrophages and neutrophils in limiting virus replication and mortality in mice. J Virol 2005; 79(23):14933-14944

89 Imai Y, Kuba K, Neely GG, et al. Identification of oxidative stress and Toll-like receptor 4 signaling as a key pathway of acute lung injury. Cell 2008;133(2):235-249

90 Tate MD, Brooks AG, Reading PC. The role of neutrophils in the upper and lower respiratory tract during influenza virus infection of mice. Respir Res 2008;9:57

91 Tate MD, Deng YM, Jones JE, Anderson GP, Brooks AG, Reading PC. Neutrophils ameliorate lung injury and the development of severe disease during influenza infection. J Immunol 2009; 183(11):7441-7450

92 Narasaraju T, Yang E, Samy RP, et al. Excessive neutrophils and neutrophil extracellular traps contribute to acute lung injury of influenza pneumonitis. Am J Pathol 2011;179(1):199-210

93 Zemans RL, Colgan SP, Downey GP. Transepithelial migration of neutrophils: mechanisms and implications for acute lung injury. Am J Respir Cell Mol Biol 2009;40(5):519-535

94 Saffarzadeh M, Juenemann C, Queisser MA, et al. Neutrophil extracellular traps directly induce epithelial and endothelial cell death: a predominant role of histones. PLoS ONE 2012; 7(2):e32366

95 Amulic B, Cazalet C, Hayes GL, Metzler KD, Zychlinsky A. Neutrophil function: from mechanisms to disease. Annu Rev Immunol 2012;30:459-489

96 Brandes M, Klauschen F, Kuchen S, Germain RN. A systems analysis identifies a feedforward inflammatory circuit leading to lethal influenza infection. Cell 2013;154(1):197-212 
97 Ichikawa A, Kuba K, Morita M, et al. CXCL10-CXCR3 enhances the development of neutrophil-mediated fulminant lung injury of viral and nonviral origin. Am J Respir Crit Care Med 2013;187(1): 65-77

98 Tavian M, Péault B. Embryonic development of the human hematopoietic system. Int J Dev Biol 2005;49(2-3):243-250

99 Fogg DK, Sibon C, Miled C, et al. A clonogenic bone marrow progenitor specific for macrophages and dendritic cells. Science 2006;311(5757):83-87

100 Sica A, Mantovani A. Macrophage plasticity and polarization: in vivo veritas. J Clin Invest 2012;122(3):787-795

101 Herold S, Mayer K, Lohmeyer J. Acute lung injury: how macrophages orchestrate resolution of inflammation and tissue repair. Front Immunol 2011;2:65

102 Högner K, Wolff T, Pleschka S, et al. Macrophage-expressed IFN- $\beta$ contributes to apoptotic alveolar epithelial cell injury in severe influenza virus pneumonia. PLoS Pathog 2013;9(2): e1003188

103 Herold S, Steinmueller M, von Wulffen W, et al. Lung epithelial apoptosis in influenza virus pneumonia: the role of macrophageexpressed TNF-related apoptosis-inducing ligand. J Exp Med 2008;205(13):3065-3077

104 Rodrigue-Gervais IG, Labbé K, Dagenais M, et al. Cellular inhibitor of apoptosis protein cIAP2 protects against pulmonary tissue necrosis during influenza virus infection to promote host survival. Cell Host Microbe 2014;15(1):23-35

105 Davidson S, Crotta S, McCabe TM, Wack A. Pathogenic potential of interferon $\alpha \beta$ in acute influenza infection. Nat Commun 2014; 5:3864

106 Peteranderl C, Morales-Nebreda L, Selvakumar B, et al. Macrophage-epithelial paracrine crosstalk inhibits lung edema clearance during influenza infection. J Clin Invest 2016;126(4): $1566-1580$

107 Unkel B, Hoegner K, Clausen BE, et al. Alveolar epithelial cells orchestrate DC function in murine viral pneumonia. J Clin Invest 2012;122(10):3652-3664

108 Ichinohe T, Pang IK, Kumamoto Y, et al. Microbiota regulates immune defense against respiratory tract influenza A virus infection. Proc Natl Acad Sci U S A 2011;108(13):5354-5359

109 GeurtsvanKessel CH, Willart MA, van Rijt LS, et al. Clearance of influenza virus from the lung depends on migratory langerin + CD11b- but not plasmacytoid dendritic cells. J Exp Med 2008;205(7):1621-1634

110 Soloff AC, Bissel SJ, Junecko BF, et al. Massive mobilization of dendritic cells during influenza A virus subtype H5N1 infection of nonhuman primates. J Infect Dis 2014;209(12):2012-2016

111 Fernandez M, Miller E, Krammer F, Greenbaum B, Bhardwaj N. Ion efflux and influenza infection trigger NLRP3 inflammasome signaling in human dendritic cells. J Leukoc Biol 2016;99(5): 723-734

112 Ichinohe T, Lee HK, Ogura Y, Flavell R, Iwasaki A. Inflammasome recognition of influenza virus is essential for adaptive immune responses. J Exp Med 2009;206(1):79-87

113 Hufford MM, Kim TS, Sun J, Braciale TJ. Antiviral CD8+ T cell effector activities in situ are regulated by target cell type. J Exp Med 2011;208(1):167-180

114 Hufford MM, Richardson G, Zhou H, et al. Influenza-infected neutrophils within the infected lungs act as antigen presenting cells for anti-viral CD8(+) T cells. PLoS ONE 2012;7(10):e46581

115 McGill J, Van Rooijen N, Legge KL. Protective influenza-specific CD8 $\mathrm{T}$ cell responses require interactions with dendritic cells in the lungs. J Exp Med 2008;205(7):1635-1646

116 Kim TS, Sun J, Braciale TJ. T cell responses during influenza infection: getting and keeping control. Trends Immunol 2011; 32(5):225-231

117 Teijaro JR, Walsh KB, Cahalan S, et al. Endothelial cells are central orchestrators of cytokine amplification during influenza virus infection. Cell 2011;146(6):980-991
118 Zeng H, Pappas C, Belser JA, et al. Human pulmonary microvascular endothelial cells support productive replication of highly pathogenic avian influenza viruses: possible involvement in the pathogenesis of human H5N1 virus infection. J Virol 2012;86(2): 667-678

119 Ocaña-Macchi M, Bel M, Guzylack-Piriou L, et al. Hemagglutinindependent tropism of H5N1 avian influenza virus for human endothelial cells. J Virol 2009;83(24):12947-12955

120 Ishiguro N, Takada A, Yoshioka M, et al. Induction of interferoninducible protein-10 and monokine induced by interferon-gamma from human endothelial cells infected with Influenza A virus. Arch Virol 2004;149(1):17-34

121 Visseren FL, Verkerk MS, Bouter KP, Diepersloot RJ, Erkelens DW. Interleukin-6 production by endothelial cells after infection with influenza virus and cytomegalovirus. J Lab Clin Med 1999;134(6): 623-630

122 Huang F, Guo J, Zou Z, et al. Angiotensin II plasma levels are linked to disease severity and predict fatal outcomes in H7N9-infected patients. Nat Commun 2014;5:3595

123 Zou Z, Yan Y, Shu Y, et al. Angiotensin-converting enzyme 2 protects from lethal avian influenza A H5N1 infections. Nat Commun 2014;5:3594

124 Teijaro JR, Walsh KB, Rice S, Rosen H, Oldstone MB. Mapping the innate signaling cascade essential for cytokine storm during influenza virus infection. Proc Natl Acad Sci U S A 2014; 111(10):3799-3804

125 Smith NM, Bresee JS, Shay DK, Uyeki TM, Cox NJ, Strikas RA; Advisory Committee on Immunization Practices. Prevention and control of influenza: recommendations of the Advisory Committee on Immunization Practices (ACIP). MMWR Recomm Rep 2006;55(RR-10)1-42

126 WHO. WHO Guidelines for Pharmacological Management of Pandemic Influenza A (H1N1) and other Influenza Viruses. 2009. Available at: www.who.int/csr/resources/publications/ swineflu/h1n1_guidelines_pharmaceutical_mngt.pdf

127 People at High Risk of Developing Flu-Related Complications. 2015. Available at: http://www.cdc.gov/flu/about/disease/high_risk.htm. Accessed August 19, 2015

128 Louie JK, Acosta M, Samuel MC, et al; California Pandemic (H1N1) Working Group. A novel risk factor for a novel virus: obesity and 2009 pandemic influenza A (H1N1). Clin Infect Dis 2011;52(3): 301-312

129 Louie JK, Acosta M, Winter K, et al; California Pandemic (H1N1) Working Group. Factors associated with death or hospitalization due to pandemic 2009 influenza A(H1N1) infection in California. JAMA 2009;302(17):1896-1902

130 Van Kerkhove MD, Vandemaele KA, Shinde V, et al; WHO Working Group for Risk Factors for Severe H1N1pdm Infection. Risk factors for severe outcomes following 2009 influenza A (H1N1) infection: a global pooled analysis. PLoS Med 2011; 8(7):e1001053

131 Shinya K, Ebina M, Yamada S, Ono M, Kasai N, Kawaoka Y. Avian flu: influenza virus receptors in the human airway. Nature 2006; 440(7083):435-436

132 van Riel D, den Bakker MA, Leijten LM, et al. Seasonal and pandemic human influenza viruses attach better to human upper respiratory tract epithelium than avian influenza viruses. Am J Pathol 2010;176(4):1614-1618

133 Mauad T, Hajjar LA, Callegari GD, et al. Lung pathology in fatal novel human influenza A (H1N1) infection. Am J Respir Crit Care Med 2010;181(1):72-79

134 Rello J, Pop-Vicas A. Clinical review: primary influenza viral pneumonia. Crit Care 2009;13(6):235

135 Rynda-Apple A, Robinson KM, Alcorn JF. Influenza and bacterial superinfection: illuminating the immunologic mechanisms of disease. Infect Immun 2015;83(10):3764-3770

136 Blyth CC, Webb SA, Kok J, et al; ANZIC Influenza Investigators; COSI Microbiological Investigators. The impact of bacterial and 
viral co-infection in severe influenza. Influenza Other Respi Viruses 2013;7(2):168-176

137 Goka E, Vallely P, Mutton K, Klapper P. Influenza A viruses dual and multiple infections with other respiratory viruses and risk of hospitalisation and mortality. Influenza Other Respi Viruses 2013;7(6):1079-1087

138 Stefanska I, Romanowska M, Donevski S, Gawryluk D, Brydak LB. Co-infections with influenza and other respiratory viruses. Adv Exp Med Biol 2013;756:291-301

139 Dobson J, Whitley RJ, Pocock S, Monto AS. Oseltamivir treatment for influenza in adults: a meta-analysis of randomised controlled trials. Lancet 2015;385(9979):1729-1737

140 Storms AD, Gubareva LV, Su S, et al; US Antiviral Resistance Surveillance Working Group. Oseltamivir-resistant pandemic (H1N1) 2009 virus infections, United States, 2010-11. Emerg Infect Dis 2012;18(2):308-311

141 Dunning J, Baillie JK, Cao B, Hayden FG; International Severe Acute Respiratory and Emerging Infection Consortium (ISARIC). Antiviral combinations for severe influenza. Lancet Infect Dis 2014;14(12):1259-1270

142 Louie JK, Yang S, Acosta M, et al. Treatment with neuraminidase inhibitors for critically ill patients with influenza A (H1N1) pdm09. Clin Infect Dis 2012;55(9):1198-1204

143 Perez-Padilla R, de la Rosa-Zamboni D, Ponce de Leon S, et al; INER Working Group on Influenza. Pneumonia and respiratory failure from swine-origin influenza A (H1N1) in Mexico. N Engl J Med 2009;361(7):680-689

144 Napolitano LM, Park PK, Raghavendran K, Bartlett RH. Nonventilatory strategies for patients with life-threatening 2009 H1N1 influenza and severe respiratory failure. Crit Care Med 2010;38 (4, Suppl):e74-e90

145 Estenssoro E, Ríos FG, Apezteguía C, et al; Registry of the Argentinian Society of Intensive Care SATI. Pandemic 2009 influenza A in Argentina: a study of 337 patients on mechanical ventilation. Am J Respir Crit Care Med 2010;182(1):41-48

146 Ventetuolo CE, Muratore CS. Extracorporeal life support in critically ill adults. Am J Respir Crit Care Med 2014;190(5):497-508

$147 \mathrm{Kim}$ SH, Hong SB, Yun SC, et al; Korean Society of Critical Care Medicine H1N1 Collaborative. Corticosteroid treatment in critically ill patients with pandemic influenza A/H1N1 2009 infection: analytic strategy using propensity scores. Am J Respir Crit Care Med 2011;183(9):1207-1214

148 Hui DS, Lee N, Chan PK. Clinical management of pandemic 2009 influenza $A(H 1 N 1)$ infection. Chest 2010;137(4):916-925

149 Jain S, Benoit SR, Skarbinski J, Bramley AM, Finelli L; 2009 Pandemic Influenza A (H1N1) Virus Hospitalizations Investigation Team. Influenza-associated pneumonia among hospitalized patients with 2009 pandemic influenza A (H1N1) virus-United States, 2009. Clin Infect Dis 2012;54(9):1221-1229

150 Morens DM, Taubenberger JK, Harvey HA, Memoli MJ. The 1918 influenza pandemic: lessons for 2009 and the future. Crit Care Med 2010;38(4, Suppl):e10-e20

151 Cortes Garcia M, Sierra Moros MJ, Santa-Olalla Peralta P, Hernandez-Barrera V, Jimenez-Garcia R, Pachon I. Clinical characteristics and outcomes of diabetic patients who were hospitalised with 2009 pandemic influenza A H1N1 infection. J Infect 2012;64(2): 218-224

152 Rodríguez-Rieiro C, Carrasco-Garrido P, Hernández-Barrera V, et al. Pandemic influenza hospitalization in Spain (2009): incidence, in-hospital mortality, comorbidities and costs. Hum Vaccin Immunother 2012;8(4):443-447

153 CDC. People at High Risk of Developing Flu-Related Complications; 2015. Available at: http://www.cdc.gov/flu/about/disease/ high_risk.htm. Accessed July 17, 2015

154 Memoli MJ, Athota R, Reed S, et al. The natural history of influenza infection in the severely immunocompromised vs nonimmunocompromised hosts. Clin Infect Dis 2014;58(2): 214-224
155 Camargo LF, de Sandes-Freitas TV, Silva CD, et al. Morbimortality of pandemic influenza A H1N1 infection in kidney transplant recipients requiring hospitalization: a comparative analysis with nonimmunocompromised patients. Transplantation 2012;93(1): 69-72

156 ANZIC Influenza Investigators and Australasian Maternity Outcomes Surveillance System. Critical illness due to 2009 A/H1N1 influenza in pregnant and postpartum women: population based cohort study. BMJ 2010;340:c1279

157 Mosby LG, Rasmussen SA, Jamieson DJ. 2009 pandemic influenza A(H1N1) in pregnancy: a systematic review of the literature. Am J Obstet Gynecol 2011;205(1):10-18

158 World Health Organization. Pregnancy and Pandemic Influenza A (H1N1) 2009: Information for Programme Managers and Clinicians; 2010. Available at: http://www.who.int/csr/resources/ publications/swineflu/h1n1_guidance_pregnancy.pdf?ua=1. Accessed July 20, 2015

159 Centers for Disease Control and Prevention (CDC). Maternal and infant outcomes among severely ill pregnant and postpartum women with 2009 pandemic influenza A (H1N1)-United States, April 2009-August 2010. MMWR Morb Mortal Wkly Rep 2011; 60(35):1193-1196

160 Forbes RL, Wark PA, Murphy VE, Gibson PG. Pregnant women have attenuated innate interferon responses to 2009 pandemic influenza A virus subtype H1N1. J Infect Dis 2012;206(5): 646-653

161 Acs N, Bánhidy F, Puhó E, Czeizel AE. Maternal influenza during pregnancy and risk of congenital abnormalities in offspring. Birth Defects Res A Clin Mol Teratol 2005;73(12):989-996

162 Seasonal influenza vaccination in Europe-Vaccination recommendations and coverage rates, 2012-2013. Available at: http:// ecdc.europa.eu/en/healthtopics/seasonal_influenza/vaccines/ Pages/vaccines.aspx. Accessed October 16, 2015

163 Albright FS, Orlando P, Pavia AT, Jackson GG, Cannon Albright LA. Evidence for a heritable predisposition to death due to influenza. J Infect Dis 2008;197(1):18-24

164 Everitt AR, Clare S, Pertel T, et al; GenISIS Investigators; MOSAIC Investigators. IFITM3 restricts the morbidity and mortality associated with influenza. Nature 2012;484(7395):519-523

165 Wang Z, Zhang A, Wan Y, et al. Early hypercytokinemia is associated with interferon-induced transmembrane protein-3 dysfunction and predictive of fatal H7N9 infection. Proc Natl Acad Sci U S A 2014;111(2):769-774

166 Mills TC, Rautanen A, Elliott KS, et al. IFITM3 and susceptibility to respiratory viral infections in the community. J Infect Dis 2014; 209(7):1028-1031

167 Williams DE, Wu WL, Grotefend CR, et al. IFITM3 polymorphism rs12252-C restricts influenza A viruses. PLoS ONE 2014;9(10): e110096

168 Ciancanelli MJ, Huang SX, Luthra P, et al. Infectious disease. Lifethreatening influenza and impaired interferon amplification in human IRF7 deficiency. Science 2015;348(6233):448-453

169 Liu Y, Li S, Zhang G, et al. Genetic variants in IL1A and IL1B contribute to the susceptibility to 2009 pandemic H1N1 influenza A virus. BMC Immunol 2013;14:37

170 Cheng Z, Zhou J, To KK, et al. Identification of TMPRSS2 as a Susceptibility Gene for Severe 2009 Pandemic A(H1N1) Influenza and A(H7N9) Influenza. J Infect Dis 2015;212(8):1214-1221

171 Chen Y, Zhou J, Cheng Z, et al. Functional variants regulating LGALS1 (Galectin 1) expression affect human susceptibility to influenza A(H7N9). Sci Rep 2015;5:8517

172 Reed C, Kim IK, Singleton JA, et al; Centers for Disease Control and Prevention (CDC). Estimated influenza illnesses and hospitalizations averted by vaccination-United States, 2013-14 influenza season. MMWR Morb Mortal Wkly Rep 2014;63(49): 1151-1154

173 Grohskopf LA, Sokolow LZ, Olsen SJ, Bresee JS, Broder KR, Karron RA. Prevention and control of influenza with vaccines: 
recommendations of the Advisory Committee on Immunization Practices, United States, 2015-16 Influenza Season. MMWR Morb Mortal Wkly Rep 2015;64(30):818-825

174 Lukashevich IS, Shirwan H, eds. Novel Technologies for Vaccine Development. Vienna: Springer; 2014

175 Clements ML, Murphy BR. Development and persistence of local and systemic antibody responses in adults given live attenuated or inactivated influenza A virus vaccine. J Clin Microbiol 1986; 23(1):66-72

176 Nunes-Alves C. Viral infection: stemming influenza viruses. Nat Rev Microbiol 2015;13(10):599

177 Impagliazzo A, Milder F, Kuipers $\mathrm{H}$, et al. A stable trimeric influenza hemagglutinin stem as a broadly protective immunogen. Science 2015;349(6254):1301-1306

178 Dempsey LA. Universal influenza vaccine. Nat Immunol 2015; 16:1013

179 Maassab HF. Biologic and immunologic characteristics of coldadapted influenza virus. J Immunol 1969;102(3):728-732

180 Beyer WE, Palache AM, de Jong JC, Osterhaus AD. Cold-adapted live influenza vaccine verss inactivated vaccine: systemic vaccine reactions, local and systemic antibody response, and vaccine efficacy. A meta-analysis. Vaccine 2002;20(9-10):1340-1353

181 Fleury D, Barrère B, Bizebard T, Daniels RS, Skehel JJ, Knossow M. A complex of influenza hemagglutinin with a neutralizing antibody that binds outside the virus receptor binding site. Nat Struct Biol 1999;6(6):530-534

182 Wei G, Meng W, Guo H, et al. Potent neutralization of influenza A virus by a single-domain antibody blocking M2 ion channel protein. PLoS ONE 2011;6(12):e28309

183 Smee DF, Bailey KW, Wong MH, et al. Treatment of influenza A (H1N1) virus infections in mice and ferrets with cyanovirin-N. Antiviral Res 2008;80(3):266-271

184 Furuta Y, Takahashi K, Shiraki K, et al. T-705 (favipiravir) and related compounds: Novel broad-spectrum inhibitors of RNA viral infections. Antiviral Res 2009;82(3):95-102

185 Furuta Y, Takahashi K, Fukuda Y, et al. In vitro and in vivo activities of anti-influenza virus compound T-705. Antimicrob Agents Chemother 2002;46(4):977-981

186 Sidwell RW, Smee DF. Peramivir (BCX-1812, RWJ-270201): potential new therapy for influenza. Expert Opin Investig Drugs 2002;11(6):859-869

187 Weight AK, Haldar J, Alvarez de Cienfuegos L, et al. Attaching zanamivir to a polymer markedly enhances its activity against drug-resistant strains of influenza a virus. J Pharm Sci 2011; 100(3):831-835

188 Mitrasinovic PM. Advances in the structure-based design of the influenza A neuraminidase inhibitors. Curr Drug Targets 2010; 11(3):315-326

189 Lin L, Liu Q, Berube N, Detmer S, Zhou Y. 5'-Triphosphate-short interfering RNA: potent inhibition of influenza A virus infection by gene silencing and RIG-I activation. J Virol 2012;86(19): 10359-10369

190 Tompkins SM, Lo CY, Tumpey TM, Epstein SL. Protection against lethal influenza virus challenge by RNA interference in vivo. Proc Natl Acad Sci U S A 2004;101(23):8682-8686

191 Loregian A, Mercorelli B, Nannetti G, Compagnin C, Palù G. Antiviral strategies against influenza virus: towards new therapeutic approaches. Cell Mol Life Sci 2014;71(19):3659-3683

192 Malakhov MP, Aschenbrenner LM, Smee DF, et al. Sialidase fusion protein as a novel broad-spectrum inhibitor of influenza virus infection. Antimicrob Agents Chemother 2006;50(4): $1470-1479$
193 Triana-Baltzer GB, Sanders RL, Hedlund M, et al. Phenotypic and genotypic characterization of influenza virus mutants selected with the sialidase fusion protein DAS181. J Antimicrob Chemother 2011;66(1):15-28

194 Triana-Baltzer GB, Gubareva LV, Klimov AI, et al. Inhibition of neuraminidase inhibitor-resistant influenza virus by DAS181, a novel sialidase fusion protein. PLoS ONE 2009;4(11):e7838

195 Kido H, Okumura Y, Yamada H, Le TQ Yano M. Proteases essential for human influenza virus entry into cells and their inhibitors as potential therapeutic agents. Curr Pharm Des 2007;13(4): 405-414

196 Ludwig S, Zell R, Schwemmle M, Herold S. Influenza, a One Health paradigm-novel therapeutic strategies to fight a zoonotic pathogen with pandemic potential. Int J Med Microbiol 2014;304(7): 894-901

197 Register ECT. Available at: https://wwwclinicaltrialsregistereu/ ctr-search/trial/2012-004072-19/DE

198 Wang X, Hinson ER, Cresswell P. The interferon-inducible protein viperin inhibits influenza virus release by perturbing lipid rafts. Cell Host Microbe 2007;2(2):96-105

199 Morita M, Kuba K, Ichikawa A, et al. The lipid mediator protectin D1 inhibits influenza virus replication and improves severe influenza. Cell 2013;153(1):112-125

200 Aver'ianov AV, Babkin AP, Bart Bla, et al. Ergoferon and oseltamivir in treatment of influenza: results of multicentre randomized comparative clinical trial [in Russian]. Antibiot Khimioter 2012;57(7-8):23-30

201 Sever-Chroneos Z, Murthy A, Davis J, et al. GM-CSF modulates pulmonary resistance to influenza A infection. Antiviral Res 2011;92(2):319-328

202 Cakarova L, Marsh LM, Wilhelm J, et al. Macrophage tumor necrosis factor-alpha induces epithelial expression of granulocyte-macrophage colony-stimulating factor: impact on alveolar epithelial repair. Am J Respir Crit Care Med 2009;180(6):521-532

203 Huang FF, Barnes PF, Feng Y, et al. GM-CSF in the lung protects against lethal influenza infection. Am J Respir Crit Care Med 2011;184(2):259-268

204 Herold S, Hoegner K, Vadász I, et al. Inhaled granulocyte/macrophage colony-stimulating factor as treatment of pneumoniaassociated acute respiratory distress syndrome. Am J Respir Crit Care Med 2014;189(5):609-611

205 Ho MS, Mei SH, Stewart DJ. The immunomodulatory and therapeutic effects of mesenchymal stromal cells for acute lung injury and sepsis. J Cell Physiol 2015;230(11):2606-2617

206 Lalu MM, Moher D, Marshall J, et al; Canadian Critical Care Translational Biology Group. Efficacy and safety of mesenchymal stromal cells in preclinical models of acute lung injury: a systematic review protocol. Syst Rev 2014;3:48

207 Wilson JG, Liu KD, Zhuo H, et al. Mesenchymal stem (stromal) cells for treatment of ARDS: a phase 1 clinical trial. Lancet Respir Med 2015;3(1):24-32

208 Weiss DJ. Cell therapies for ARDS: a promising start. Lancet Respir Med 2015;3(1):2-3

209 Leeman KT, Fillmore CM, Kim CF. Lung stem and progenitor cells in tissue homeostasis and disease. Curr Top Dev Biol 2014; 107:207-233

210 Vaughan AE, Brumwell AN, Xi Y, et al. Lineage-negative progenitors mobilize to regenerate lung epithelium after major injury. Nature 2015;517(7536):621-625

211 Quantius J, Schmoldt C, Vazquez-Armendariz I, et al. Influenza Virus infects epithelial stem/progenitor cells of the distal lung: impact on Fgfr2b-driven epithelial repair. PLOS Pathog 2016; in press 